\title{
Does rainforest logging threaten marine turtles?
}

\author{
William F. Laurance, J. Michael Fay, Richard J. Parnell \\ Guy-Philippe Sounguet, Angela Formia and Michelle E. Lee
}

\begin{abstract}
Industrial logging is expanding rapidly in Central African rainforests. We suggest that logging operations in this region pose an indirect threat to nesting marine turtles, especially the Critically Endangered leatherback turtle Dermochelys coriacea. This occurs because some logs are being lost or abandoned during downriver transport to coastal timber yards; the lost logs float out to sea and then often wash ashore, where they accumulate on beaches used by nesting turtles. We used a light aircraft to survey logs along the entire coastline of Gabon, and also studied the impacts of logs at Pongara Beach, one of the world's most important turtle nesting areas, during the 2002-2003 and 2003-2004 breeding seasons. Nearly 11,000 lost logs were counted along Gabon's beaches, with an estimated commercial value of USD 11.1 million. Logs were unevenly distributed along the coast, reaching a peak density of $247 \operatorname{logs~} \mathrm{km}^{-1}$. At Pongara, logs blocked $30.5 \%$ of the beach. These logs had a number of negative effects on marine turtles, causing $8-14 \%$ of all nesting attempts $(n=2,163)$ to be aborted or disrupted. Initiatives to remove lost logs and driftwood from critical nesting beaches may be the most effective means to reduce their deleterious impacts on threatened marine turtles.
\end{abstract}

Keywords Africa, beaches, Dermochelys coriacea, Gabon, leatherback, logging, marine turtle, nesting, rainforest.

\section{Introduction}

Tndustrial logging is growing rapidly in Central African rainforests (Collomb et al., 2000; Weber et al., 2001; Laurance et al., 2006). Logging operations have important ecological impacts on tropical rainforests, such as fragmenting forest canopy cover, reducing populations of wildlife sensitive to disturbance, accelerating soil erosion and stream sedimentation, and increasing the likelihood of wildfires (Johns, 1997; Fimbel et al., 2001; Siegert et al., 2001).

William F. Laurance* (Corresponding author) Smithsonian Tropical Research Institute, Apartado 0843-03092, Balboa, Ancón, Panama. E-mail laurancew@si.edu

J. Michael Fay*, Richard J. Parnell and Angela Formia Wildlife Conservation Society-Gabon, B.P. 7847, Libreville, Gabon.

Guy-Philippe Sounguet Aventures Sans Frontières, B.P. 7248, Libreville, Gabon.

Michelle E. LeE Monitoring and Assessment of Biodiversity Program, National Zoological Park, Smithsonian Institution, P.O. Box 37012, Washington, DC, 20560-0705, USA.

${ }^{\star}$ Contributed equally to this work.

Received 18 November 2006. Revision requested 19 December 2006 Accepted 9 May 2007.
Here we describe a largely unanticipated environmental risk of tropical logging: the rapid accumulation of lost timber along beaches and waterways (see also Fretey \& Girardin, 1988). In addition to being a source of economic waste, we believe lost logs are a potential threat to marine turtles.

In much of the tropics harvested logs from timber operations are transported via rivers to coastal areas for export or processing. Logs are loaded onto barges or cabled together into floating rafts that can involve up to several thousand trunks (Johns, 1997; Fimbel et al., 2001). These logs are occasionally lost during transport and yarding near timber mills, and defective logs may be abandoned in waterways by unscrupulous timber operators. Floating logs can damage coral reefs (Dethier, 1984) and are a hazard for boat traffic and people on beaches. In tropical nations a number of small boat and ferry accidents and deaths have been attributed to collisions with floating logs (Anon., 2000, 2001).

Like several other Central African nations, Gabon is experiencing a major timber boom (Collomb et al., 2000; Laurance et al., 2006) and there is a large accumulation of lost logs along its beaches and waterways. Marine turtles, which must nest above the high tide line on beaches to be successful, and move laboriously on land (Leslie et al., 1996; Woller et al., 2000), appear especially vulnerable to beached logs. Gabon is one of the world's most important nesting areas for the leatherback turtle Dermochelys coriacea, as well as for olive ridley Lepidochelys olivacea, green Chelonia mydas, and hawksbill Eretmochelys imbricata turtles (Sounguet, 2004). In recent decades global leatherback turtle populations have declined precipitously as a result of entanglement in fishing gear, hunting, nest robbing, ingestion of plastic debris, and other causes (Spotila et al., 1996, 2000; Eckert, 1997; Ferraroli et al., 2004), and the species is now categorized as Critically Endangered on the IUCN Red List (IUCN, 2007).

Here we provide an initial assessment of threats to nesting marine turtles posed by accumulated logs on Gabonese beaches. Firstly, we used a light aircraft to survey logs on almost all beaches along Gabon's 1,014-km coastline. Secondly, we measured all logs blocking Pongara Beach in Gabon, which is one of the world's most important nesting areas for leatherback turtles, with up to 1,839 nesting attempts recorded in a single breeding season (Sounguet, 2004). Finally, we estimated the impacts of logs on nesting turtles at Pongara during the 2002-2003 and 2003-2004 nesting seasons.

\section{Methods}

About two-thirds of Gabon's forests are currently in logging concessions (c. 12 million ha), with harvest levels 
presently exceeding 500,000 trees annually (c. 2.7 million $\mathrm{m}^{3}$ of roundlogs; Collomb et al., 2000; Laurance et al., 2006). Most logs from inland forests are transported to the coast, either by road or on log rafts down the Ogooué River. Once at the coast, logs are marshalled into large holding areas before being cut into timber or loaded onto ships for export.

Aerial surveys of logs on Gabonese beaches were conducted during daylight hours on 11-12 January 2003, using a Cessna 182 light aircraft. The plane flew at a steady groundspeed $\left(180-200 \mathrm{~km} \mathrm{hr}^{-1}\right)$ at $c .80 \mathrm{~m}$ altitude, beginning in northern Gabon on the national border with Equatorial Guinea and proceeding southward to the national border with the Republic of Congo. The entire coastline of Gabon was surveyed but our focus was on areas of beach (including coastal dunes) that provide potential nesting habitat for marine turtles. Areas that were not surveyed included an expanse of mangroves and mudflats north and east of Port Gentil, which did not support nesting turtles, and a $20 \mathrm{~km}$ wide, no-fly zone around the capital city of Libreville (this area, near the mouth of the Como River, has a high density of beached logs).

We recorded logs on beaches using a video camera linked via a time stamp on the images to data from a global positioning system (GPS) with external antenna. We divided the beaches into a total of 1,034 segments of $c .600 \mathrm{~m}$ each (mean $619 \pm$ SD $36 \mathrm{~m}$ ) using GPS way points, and counted the number of logs in each segment. Logs were generally 3-15 $\mathrm{m}$ in length and 50-120 $\mathrm{cm}$ in diameter (see below). Densities of beached logs 20-30 km south of Port Gentil were reduced by sawing and removal of logs in that area, as evidenced by low log numbers and clear evidence of harvest activity (cut pieces and stacks of logs). Data on log densities for each beach segment were imported into the geographical information system ArcView v. 3.2 (ESRI, Redlands, USA), which was used to produce maps of the distribution of beached logs along the coastline.

We also estimated the commercial value of lost timber on Gabonese beaches. Nearly three quarters of all timber exploited in Gabon is okoumé Aucoumea klaineana, a valuable species used for plywood and construction timber (Collomb et al., 200o). Most okoumé and other Gabonese timbers are exported as roundlogs, especially to China and other Asian nations (Collomb et al., 2000). We determined the typical commercial value for okoumé roundlogs using internet sources. Values were USD $169-286 \mathrm{~m}^{-3}$, and we used the midpoint (USD 228) to estimate the potential commercial value of beached logs. We determined the typical volume of beached logs (mean $4.42 \pm \mathrm{SD} 3.11 \mathrm{~m}^{3}$ ) by measuring the length and diameter of a total of 166 logs along four beaches in northern and southern Gabon.

In March 2005 we determined the amount of beachfront at Pongara Beach that was directly blocked to nesting marine turtles by lost logs. We focused on a $4.2 \mathrm{~km}$-long segment of beach (south-west of Pointe Denis) that has one of the highest nesting densities of leatherback turtles in the world (Sounguet, 2004). We included only logs or driftwood that were $\geq 20 \mathrm{~cm}$ in diameter and $\geq 3.5 \mathrm{~m}$ in length; smaller logs and individual pieces of driftwood were not considered a barrier to marine turtles. We used a measuring tape to determine the length of each blockage, which was constituted by a single log or pile of logs. Gaps between nearby logs had to be $\geq 2 \mathrm{~m}$ in width (larger than the combined body and flipper width of a leatherback) to be considered open access to the beach. For logs that were not parallel to the beach, we considered only the parallel distance to be blocked to turtles.

Along the same section of Pongara Beach we estimated the impacts of logs on female marine turtles during the 2002-2003 and 2003-2004 nesting seasons (NovemberMarch), as part of a larger study of this population (Sounguet, 2004). Data on the incidence of turtles entangled in logs (found dead and wedged into log piles) and of aborted nesting attempts (in which the female returned to the sea without nesting) were recorded during both nesting seasons. In the second nesting season, we also attempted to determine (a) whether logs were responsible for any aborted nesting attempts (whereby the female failed to circumvent the blockage and then returned to the sea without nesting), (b) the incidence of nests constructed too near the waterline to be viable, because of log blockage, and (c) the number of disoriented turtles that failed to return to the sea and were found in inland savannah during the daytime (i.e. apparently because logs blocked their view of the sea, which is brighter than the land at night).

The effects of logs were inferred each day from early morning surveys of turtle tracks and nest diggings made the previous night. Although all observations were recorded by trained field teams, some uncertainty in our estimates of log impacts was unavoidable given that turtle nesting attempts were not observed directly. For this reason we discriminated between cases in which logs clearly affected turtle nesting and those in which an effect was considered likely but could not be inferred with certainty.

\section{Results}

During our aerial survey we counted 10,969 logs on Gabon's beaches, averaging $17.1 \pm$ SD $29.6 \operatorname{logs~} \mathrm{km}^{-1}$. Logs were not evenly distributed but were clumped in two broad zones in the northern and southern parts of the country, reaching a peak density of $247 \mathrm{logs} \mathrm{km}^{-1}$ (Fig. 1). The two zones encompassed about half of the total coastline and included both Pongara and Mayumba, the two most important turtle nesting beaches in Gabon. Beached logs were usually parallel to the waterline but sometimes formed large tangles at high densities. Overall, an estimated $48,483 \mathrm{~m}^{3}$ of lost logs, with a commercial value of nearly USD 11.1 million, were detected. At the critical Pongara nesting area $30.5 \%$ of 
the beach was blocked by 64 logs or log piles that were 3.5-290 m in length (mean $19.8 \pm$ SD $39.9 \mathrm{~m}$ ).

In the 2002-2003 and 2003-2004 breeding seasons we recorded a total of 2,163 nesting attempts at Pongara Beach, mostly by leatherback turtles (2,111 attempts), and the remainder by olive ridley (49 attempts) and green (3 attempts) turtles. For unknown reasons total nesting activity at Pongara was much greater in 2002-2003 (1,817 attempts) than 2003-2004 (294 attempts). At Mayumba Beach nesting activity along a $10-\mathrm{km}$ transect also declined in 2003-2004 relative to 2002-2003 but to a lesser degree (from 2,898 to 1,710 attempts; unpubl. data, Aventures Sans Frontières).

We observed beached logs to have at least four deleterious effects on nesting marine turtles. Firstly, even a single log can create an impassable barrier for adult females attempting to nest, causing the nesting attempt to be aborted and the female to return to the sea (a phenomenon termed a false crawl; Plate 1a). Although such females may later renest in another location, the increased time, energetic costs, physiological stress, and predation risk may be considerable (Woller et al., 2000; Sounguet, 2004). Based on our interpretation of turtle activity at Pongara, 1.4\% (4 of 294) of nesting attempts were clearly aborted because of logs (Plate 1a), and another $2.7 \%$ (8 of 294) were possibly aborted because of logs (i.e. the turtle aborted the nesting attempt within 2-3 $\mathrm{m}$ of a log blockage but we could not conclude with certainty that the logs were responsible).

Secondly, when impeded by logs, some females nest closer to the waterline than normal. A total of $6.1 \%$ (18 of 294) of nest locations at Pongara were clearly altered by logs, almost always being closer than normal to the waterline. Another 2.4\% (7 of 294) of nest locations were possibly affected by logs, again being closer than normal to the waterline. These disrupted nesting attempts are especially problematic because the eggs can be quickly killed by

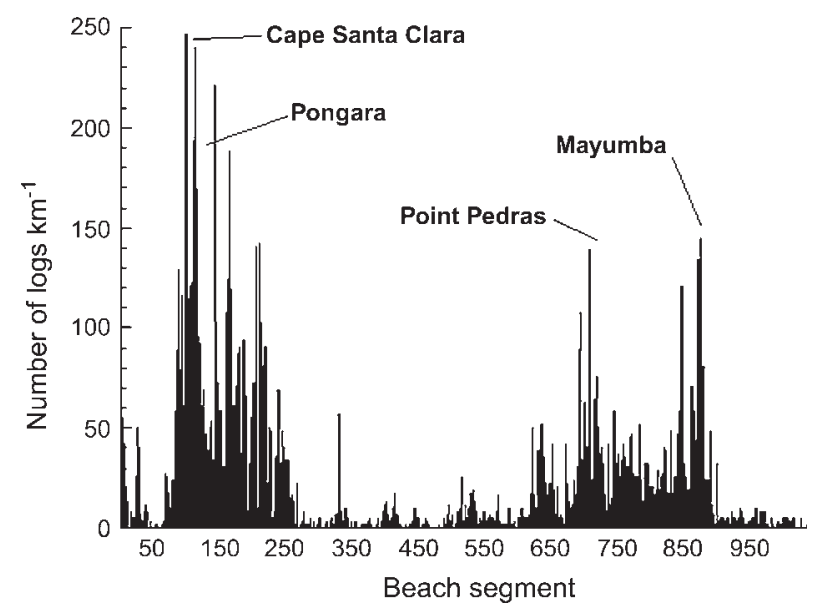

FIG. 1 Density of beached logs by beach segment (each segment was $619 \mathrm{~m}$ long on average; see text for details) along Gabonese beaches in early 2003, from north to south. Pongara and Mayumba are the most important marine turtle nesting beaches in Gabon. seawater inundation. During the typical incubation period of 56-68 days (Hirth, 1980; Chacón, 1999) leatherback turtle nests must be located high enough on beaches to withstand a range of tidal amplitudes.

Thirdly, adult turtles can become wedged or trapped by logs, causing death by heat exhaustion or predation (Plates $1 b, c, 2)$. Overall, $0.2 \%$ (5 of 2,163) of the nesting turtles at Pongara became entangled in logs and died (or would have died had they not been rescued). Finally, some turtles become disoriented because logs evidently block their view of the sea, and crawl inland, where they are likely to die, rather than returning to the sea after nesting. In total 1.0\% ( 3 of 294) of the observed nesting turtles became disoriented at Pongara and were found in inland savannah during the day (all were rescued; lights from a small resort near the beach also seemingly contributed to disorientation of a few turtles). Thus, $c .1 .2 \%$ of all nesting individuals were trapped or disoriented by logs, which is typically fatal.

Overall, we infer that $8-14 \%$ of all nesting attempts at Pongara Beach, most (97.6\%) involving leatherback turtles, were disturbed or thwarted by lost logs, sometimes with fatal effects for the nesting female. In addition to the effects of logs, another 7.1\% (21 of 294) of nest attempts at Pongara were aborted for reasons unrelated to logs (often because turtles were unable to climb or circumvent abrupt steps caused by sand erosion patterns on the beach).

\section{Discussion}

The results of our study suggest that, along one of the world's most important marine turtle nesting beaches, $8-14 \%$ of all nesting attempts are being disrupted by lost or abandoned logs that largely originate from inland timber operations. The most frequent impacts of log obstructions on beaches involve females either digging their nests below the high tide line, where their eggs would almost certainly be killed by seawater inundation, or aborting their nesting attempts altogether. In addition, c. $1.2 \%$ of all nesting individuals were trapped or disoriented by logs. This figure may appear insubstantial but for long-lived animals with delayed maturation such as marine turtles, even small increases in adult mortality could potentially have a significant impact on population viability (Crouse et al., 1987; Kendall \& Nichols, 2002).

Our study provides only a minimum estimate of the impacts of lost logs on marine turtles. Firstly, it does not include the deleterious effects of logs on hatchlings, which emerge at night and are vulnerable to terrestrial predators as they head to the sea. Hatchlings that are impeded or confused by logs are likely to suffer increased crab and seabird predation, or be killed by heat exhaustion if they are unable to reach the sea before daytime. Circumventing log barriers could also sap the limited energy from nestlings needed in the swimming frenzy that allows them to escape 

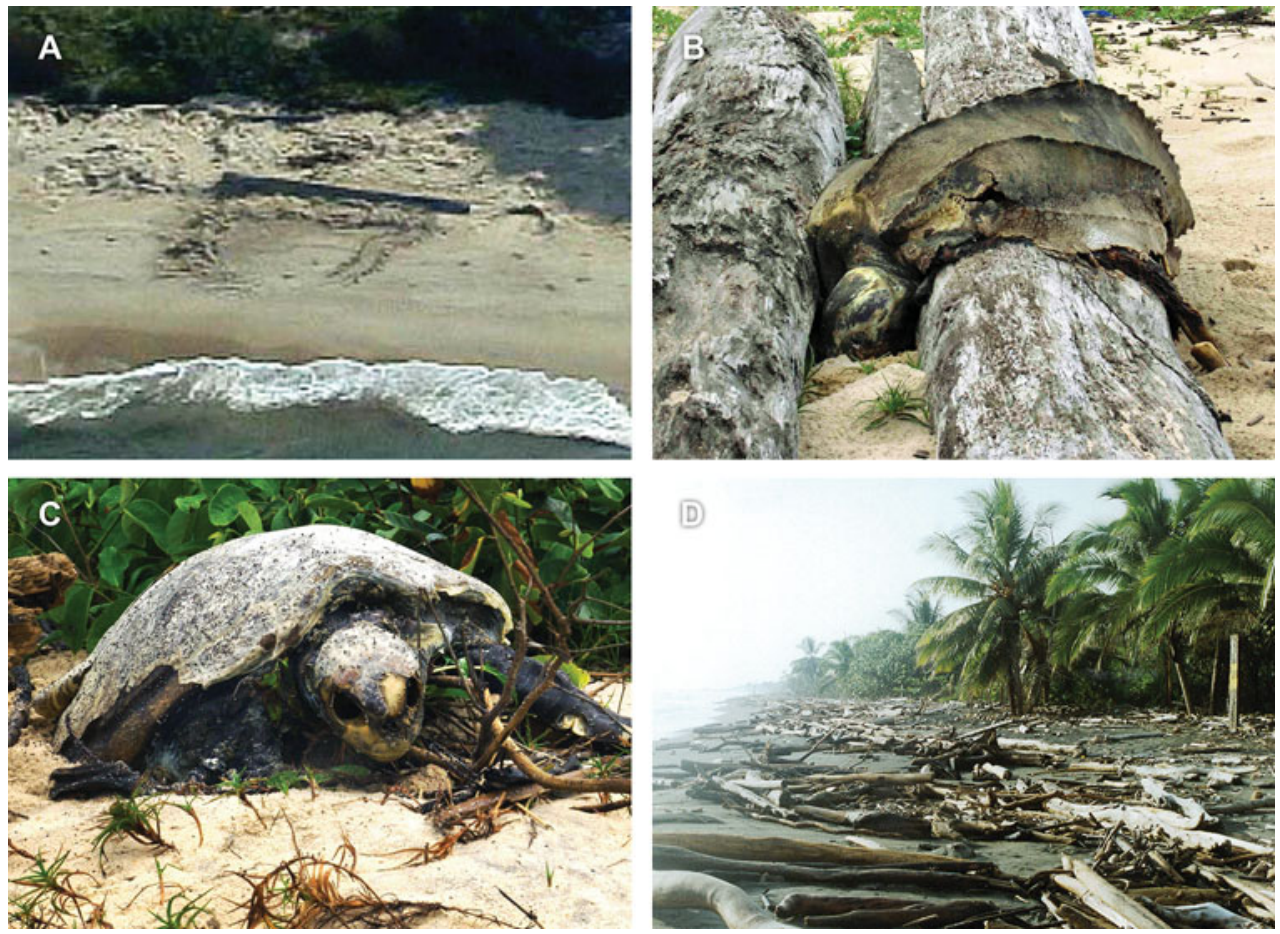

Plate 1 (a) Video image showing an aborted nesting attempt by a marine turtle after being blocked by a beached log (by J. Michael Fay); remains of a (b) female leatherback turtle and (c) female olive ridley turtle that became trapped and died at Pongara Beach (by Guy-Philippe Sounguet and Andrew Coates, respectively); (d) densely accumulated driftwood, which results in part from nearby deforestation, at Gandoca Beach in Costa Rica (by Didier Chacón).

coastal waters rich in predators. Secondly, it does not include the potential for wave-tossed logs to crush adult and hatchling turtles, as has been observed for other coastal wildlife such as crocodiles (Pauwels et al., 2004). Given such limitations in our analysis, it would be highly desirable to expand future studies of turtle-log interactions in scope and duration, and to include other critical nesting beaches, such as Mayumba, in these investigations.

In Gabon lost timber on beaches is owned by the government and cannot be legally removed without a permit from the Gabon Forestry Department. This may discourage harvesting of beached logs for timber or firewood by local residents, although we observed some illegal harvesting. Revoking the current restriction on harvesting beached timber could potentially facilitate log removal but such operations may degrade beaches if tractors or other heavy equipment are not used carefully. One option would be to allow local communities or contractors to remove timber from critical nesting beaches but only under the supervision of NGOs working locally to promote turtle conservation. Such organizations could ensure that timber removal operations were conducted outside the turtle nesting season, and that all efforts were made to minimize physical damage to beaches.

The proliferation of beached logs in Gabon typifies a wider problem of excessive waste and inefficiency in the tropical timber industry (Klassen, 1994; Putz et al., 2000;

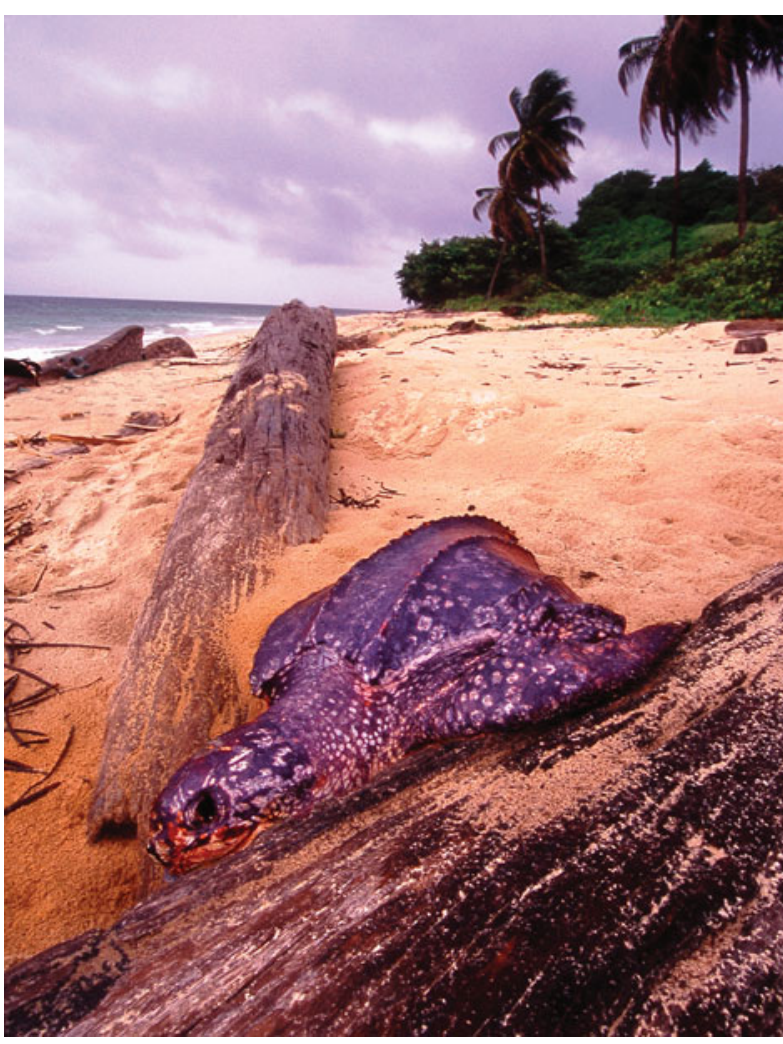

Plate 2 A female leatherback turtle trapped by beached logs at Pongara Beach. The turtle's eyes were removed by ghost crabs (photo (C) David Liggett). 
Fimbel et al., 2001; Baker et al., 2004). Our general sense is that the accumulation of lost timber along beaches and waterways is most apparent in the African and Asian tropics, such as in Gabon, Equatorial Guinea, Republic of Congo, and Malaysian and Indonesian Borneo, possibly because many of the hardwoods in these areas (e.g. Asian dipterocarps, African okoumé and mahoganies) are light enough to be rafted down rivers. The lost timber we documented does not include (a) additional waste from logs that were beached in mangrove forests and mudflats, which were not surveyed in our study; (b) logs that were lost at sea or became waterlogged and sank; and (c) usable timber that is wasted or poorly utilized during harvest and milling operations (Klassen, 1994; Putz et al., 2000). In the long-term, such inefficiency exacerbates pressures on remaining forests, many of which are being rapidly overharvested (Collomb et al., 2000; Laurance et al., 2006).

Globally, beached logs are not the only obstacles for nesting marine turtles. In Central America, for example, nesting turtles are impeded by dense driftwood (Plate 1d), which is evidently increased by nearby deforestation and landslides, and by plastics and other human refuse on beaches (Chacón et al., 1996; Ruiz et al., 2005). Given the rapid pace of tropical logging and deforestation (Laurance \& Peres, 2006) and the myriad sources of plastics and other human refuse in oceans (Hansen, 1990), the most effective way to reduce such ubiquitous threats to nesting turtles, we believe, will be to remove wood and other debris from critical nesting beaches. Such efforts are underway in only a few localities (Chacón et al., 1996; Chacón, 1999) and, to our knowledge, have never been attempted at any turtle nesting beach in Africa.

In general, our findings bolster the notion that important linkages exist between terrestrial and marine ecosystems (Laurance \& Peres, 2006). Coral reefs, for example, can be seriously degraded by sedimentation from nearby deforestation (Bryant et al., 1998) and by algal blooms caused by phosphate and nitrogen pollution (Carpenter et al., 1998; Pandolfi et al., 2005). In coastal West Africa depletion of marine fisheries has led to increased hunting pressure on terrestrial wildlife (Brashares et al., 2004). The rapid destruction of mangrove forests, which provide nurseries for many fish and shrimp species, is having serious impacts on coastal fisheries (Valiela et al., 2001). Plastic waste is pervasive in the world's oceans and is a particular threat to leatherback turtles, which can choke to death on plastic debris they mistake for jellyfish, their principle food (Anon., 2005). Finally, in the Gulf of Guinea, we have observed that human predation on marine turtles and their eggs is increasing as artisanal fisheries decline because of overharvesting by industrial trawlers and the destruction of coastal mangrove forests.

In the near future, logging in Central Africa is likely to increase sharply as a result of current plans, backed by the
World Bank, to increase industrial timber harvests by as much as 6o-fold in the vast Democratic Republic of Congo (Anon., 2004). Unless managed carefully, such operations could have important impacts not only on native forests but also on coastal ecosystems and threatened marine turtles.

\section{Acknowledgements}

We thank Didier Chacón, Sarah Otterstrom, Robert Ewers and two anonymous referees for commenting on the article, and David Liggett, Didier Chacón and Andrew Coates for use of photographs. The Wildlife Conservation Society and Smithsonian Institution provided support. This is publication number 90 in the Smithsonian Monitoring and Biodiversity Program series.

\section{References}

Anon. (2000) Miracle saves Assam ferry. Assam and the Northeast Newsletter, 12 June [http://www.axom.faithweb.com/flood/ juni.html 17, accessed 2 July 2006].

Anon. (2001) Floating log kills boy in eastern Cape. Financial Times, South Africa, 5 March.

Anon. (2004) New Threats to the Forests and Forest Dwelling Peoples of the Democratic Republic of Congo. The Rainforest Foundation, London, UK.

Anon. (2005) The Leatherback Turtle. Oceanic Resource Foundation, Winnipeg, Canada [http://www.orf.org/turtles_leatherback.htm, accessed 15 June 2006].

Baker, M., Clausen, R., Kanaan, R., N'Goma, M., Roule, T. \& Thomson, J. (2004) Conflict Timber: Dimensions of the Problem in Asia and Africa, Volume III: African Cases. US Agency for International Development, Washington, DC, USA.

Brashares, J.S., Arcese, P., Sam, M.K., Coppolillo, P.B., Sinclair, A.R.E. \& BAlmford, A. (2004) Bushmeat hunting, wildlife declines, and fish supply in west Africa. Science, 306, $1180-1183$.

Bryant, D., Burke, L., McManus, J. \& Spalding, M. (1998) Reefs at Risk: A Map-Based Indicator of Threats to the World's Coral Reefs. World Resources Institute, Washington, DC, USA.

Carpenter, S.R., Caraco, N.F., Correll, D.L., Howarth, R.W., Sharpley, A.N. \& S Mith, V.H. (1998) Nonpoint pollution of surface waters with phosphorus and nitrogen. Ecological Applications, 8, 559-568.

Chacón, D. (1999) Anidación de la tortuga Dermochelys coriacea (Testudines: Dermochelyidae) en playa Gandoca, Costa Rica (1990 a 1997). Revista de Biologia Tropical, 47, 225-233.

Chacón, D., Mclarney, W., Ampie, C. \& Venegas, B. (1996) Reproduction and conservation of the leatherback turtle Dermochelys coriacea (Testudines: Dermochelyidae) in Gandoca, Costa Rica. Revista de Biologia Tropical, 44, 853-860.

Collomb, J.G., Mikissa, J.B., Minnemeyer Mudunga, S., Nzao Nzao, H., Madouma, J., Mapaga, J.D. et al. (2000) A First Look at Logging in Gabon. Global Forest Watch, World Resources Institute, Washington, DC, USA.

Crouse, D.T., Crowder, L.B. \& Caswell, H. (1987) A stage-based population model for loggerhead sea turtles and implications for conservation. Ecology, 68, 1412-1423.

Dethier, M.N. (1984) Disturbance and recovery in intertidal pools: maintenance of mosaic patterns. Ecological Monographs, 54, 99-118. 
Eckert, S.A. (1997) Distant fisheries implicated in the loss of the world's largest leatherback nesting population. Marine Turtle Newsletter, 78, 2-6.

Ferraroli, S., Georges, J.-Y., Gaspar, P. \& Le Maho, Y. (2004) Endangered species: where leatherback turtles meet fisheries. Nature, 421, 521-522.

Fimbel, R., Robinson, J.G. \& Grajal, R. (eds) (2001) The Cutting Edge: Conserving Wildlife in Logged Tropical Forests. Columbia University Press, New York, USA.

Fretey, J. \& Girardin, N. (1988) La nidification de la tortue luth, Dermochelys coriacea (Vandelli, 1761)(Chelonii, Dermochelyidae) sur les côtes du Gabon. African Journal of Zoology, 102, 125-132.

Hansen, J. (1990) American Fisheries Society draft position statement on plastic debris in marine environments. Fisheries, $15,16-17$.

Hirth, H.F. (1980) Some aspects of the nesting behavior and reproductive biology of sea turtles. American Zoologist, 20, 507-523.

IUCN (2007) 2007 IUCN Red List of Threatened Species. IUCN, Gland, Switzerland. Http://www.iucnredlist.org [accessed 24 January 2007].

Johns, A.G. (1997) Timber Production and Biodiversity Conservation in Tropical Rain Forests. Cambridge University Press, Cambridge, UK.

Kendall, W. \& Nichols, J.D. (2002) Estimating state-transition probabilities for unobservable states using mark-recapture/ resighting data. Ecology, 83, 3276-3284.

Klassen, A.W. (1994) Avoidable Logging Waste. US Agency for International Development, Jakarta, Indonesia.

Laurance, W.F., Alonso, A., Lee, M. \& Campbell, P. (2006) Challenges for forest conservation in Gabon, central Africa. Futures, 38, 454-470.

Laurance, W.F. \& Peres, C.A. (eds) (2006) Emerging Threats to Tropical Forests. University of Chicago Press, Chicago, USA.

Leslie, A.J., Penick, D.N., Spotila, J.R. \& Paladino, F.V. (1996) Leatherback turtle, Dermochelys coriacea, nesting and nest success at Tortuguero, Costa Rica in 1990-1991. Chelonian Conservation Biology, 2, 159-168.

Pandolfi, J.M., Jackson, J.B.C., Baron, N., Bradbury, R.H., Guzman, H.M., Hughes, T.P. et al. (2005) Are US coral reefs on the slippery slope to slime? Science, 307, 1725-1726.

Paunels, O., Branch, W. \& Burger, M. (2004) Reptiles of Loango National Park, Ogooué-Maritime Province, south-western Gabon. Hamadryad, 29, 115-127.

Putz, F.E., Dykstra, D.P. \& Heinrich, R. (2000) Why poor logging practices persist in the tropics. Conservation Biology, 14, 951-956.
Ruiz, A., Rubén, A.M.H. \& Diaz, M. (2005) Plan de Acción para la Recuperación de las Tortugas Marinas en Panamá. Caribbean Programme, UN Environment Programme, Panama City, Panama.

Siegert, F., Ruecker, G., Hinrichs, A. \& Hoffmann, A.A. (2001) Increased damage from fires in logged forests during droughts caused by El Niño. Nature, 414, 437-440.

Sounguet, G.-P. (2004) Rapport d'activités Programme Tortues Marines: Site de Pongara, Saison 2003-2004. Aventures Sans Frontières, Libreville, Gabon.

Spotila, J.R., Dunham, A., Leslie, A., Steyermark, A., Plotkin, P. \& Paladino, F. (1996) Worldwide population decline of Dermochelys coriacea: are leatherback turtles going extinct? Chelonian Conservation Biology, 2, 209-222.

Spotila, J.R., Reina, R.D., Steyermark, A.C., Plotkin, P.T. \& Paladino, F.V. (2000) Pacific leatherback turtles face extinction. Nature, 405, 529-530.

Valiela, I., Bowen, J.L. \& York, J.K. (2001) Mangrove forests: one of the world's threatened major tropical environments. BioScience, 51, 807-851.

Weber, W., White, L.J.T., Vedder, A. \& Naughton-Treves, N. (eds) (2001) African Rain Forest Ecology and Conservation. Yale University Press, New Haven, USA.

Woller, M.J., Al Kindi, A.Y. \& Mahmoud, I.-Y. (2000) Catecholamine response in sea turtles during nesting. Society of Neuroscience Abstracts, 26, no. 143.7.

\section{Biographical sketches}

William Laurance is a past President of the Association for Tropical Biology and Conservation. His research focuses on the impacts of intensive land uses, such as habitat fragmentation, logging, and wildfires, on tropical ecosystems. He has active research programmes in the Amazon, Central Africa and tropical Australia. J. Michael Fay is the initiator of the Mega-Transect and MegaFlyover field surveys in Central African forests, and played a key role in establishing protected areas in Central Africa and initiating the Congo Basin Forest Partnership. Rich ARd PARnell is director of the Mayumba Project of the Wildlife Conservation Society. Mayumba National Park in Gabon protects one of the most important leatherback turtle nesting beaches in the world. Guy-PHiLippe SoUNGUET is president of Aventures sans Frontières, an NGO in Gabon devoted to the study and conservation of marine turtles. Angela Formia has worked extensively on marine turtle biology and coastal and marine conservation issues. Michelle LeE formerly worked with the Smithsonian Institution's Monitoring and Biodiversity Program in Gabon. 